\title{
Apoptotic effects of thymol, a novel monoterpene phenol, on different types of cancer
}

\author{
Elbe $\mathrm{H}^{1}$, Yigitturk $\mathrm{G}^{1}$, Cavusoglu $\mathrm{T}^{2}$, Uyanikgil $\mathrm{Y}^{2}$, Ozturk $\mathrm{F}^{1}$ \\ Mugla Sitki Kocman University, Faculty of Medicine, Department of Histology and Embryology, \\ Mugla, Turkey.hulya.elbe@mu.edu.tr
}

\begin{abstract}
BACKGROUND: Cancer is a major public health problem in many areas of the world. Many anticancer drugs in current clinical use have been isolated from plant species or are based on such substances. Thymol (5-methyl-2-isopropylphenol) is an oxygenated aromatic compound from monoterpene group. It is the main constituent of thyme essential oil and shows antioxidant, antiseptic and antiproliferative properties. The aim of this study is to determine the antiproliferative activity and apoptotic effect of thymol on prostate cancer (PC-3, DU145), breast cancer (MDA-MB-231), and lung cancer (KLN205) cell lines.

METHODS: The cancer cells were treated with different concentrations of thymol $(100,200,400,600,800$

$\mu \mathrm{M})$ at $24 \mathrm{~h}, 48 \mathrm{~h}$ and $72 \mathrm{~h}$. The cell viability was investigated by MTT assay and analysis of apoptosis was determined with annexin $\mathrm{V}$ assay.

RESULTS: The study showed the dose and time-dependent cytotoxic effect of thymol in PC-3, DU145,

MDA-MB-231, and KLN205 cancer cell lines. Thymol significantly induced apoptosis in all groups in a dosedependent manner. Statistical analysis showed a significant difference between thymol-treated cell lines compared to the control $(p<0.001)$.

CONCLUSION: The data in the present study demonstrated that thymol has apoptotic and antiproliferative properties in lung, breast and prostate cancer cell lines. Thymol could serve as a potential therapeutic agent in the future (Fig. 5, Ref. 26). Text in PDF www.elis.sk.

KEY WORDS: apoptosis, thymol, cancer, antiproliferative.
\end{abstract}

\section{Introduction}

Cancer is a major public health problem in many areas of the world (1). Lung cancer is the leading cause of cancer-related mortality worldwide, in both men and women. Non-small cell lung cancer (NSCLC) accounts for $\sim 85 \%$ of all lung cancer cases $(2$, 3 ). Prostate cancer is one of the most common malignancies in men and the second leading cause of death from cancer after lung cancer $(4,5)$. Breast cancer, is the most frequently occurring cancer in women and the major cause of cancer deaths worldwide (1).

Several agents including life habits, exposure to chemical agents, and diet have been correlated with risk of cancer development (6). Besides, pharmacological or nutritional intervention can significantly affect patients' quality of life by delaying cancer progression (7). Therefore, the role of dietary components in prevention of the onset and progression of cancer is an area of scientific

${ }^{1}$ Mugla Sitki Kocman University, Faculty of Medicine, Department of Histology and Embryology, Mugla, Turkey, and ${ }^{2}$ Ege University, Faculty of Medicine, Department of Histology and Embryology, Izmir, Turkey; Ege University \& Cord Blood, Cell and Tissue Research and Application Centre, Izmir, Turkey

Address for correspondence: H. Elbe, MD, Mugla Sitki Kocman University Faculty of Medicine, Department of Histology and Embryology, Mugla, Turkey.

Phone: +90.252 .2115203$ and clinical interest (4). The plant-derived products are expected to induce lesser side effects compared to synthetic drugs (8). Many anticancer drugs in current clinical use have been isolated from plant species or are based on such substances (9). A plant-derived compound, essential oil, is one among the most valuable plant products used in medicine and complementary treatment strategies (8).

Extensive researches about biologically active compounds from essential oils have proven to be potential antibacterial, antifungal and antioxidant agents (10). Accumulating data have revealed the anticarcinogenic activity of plant-derived monoterpenes $(8,9)$. Thymol (2-isopropyl-5-methylphenol) is a major phenolic compound which is present in the essential oils of various plants, including Thymus vulgaris (11). Several biological properties of thymol were reported, namely that it has anti-inflammatory, antibacterial, antispasmodic, and antioxidant effects. It is also a compound that actively inhibits cancer cells $(11,12,13)$.

In the present study, we aimed to investigate the effects of thymol on non-small cell lung cancer cell line (KLN205), human prostate cancer cell lines (PC-3 and DU145) and highly metastatic breast cancer cell line (MDA-MB-231).

\section{Materials and methods}

Two prostate cancer cell lines (PC-3, DU145), non-small cell lung cancer line (KLN205), and a highly metastatic human 
PC-3 Cell line

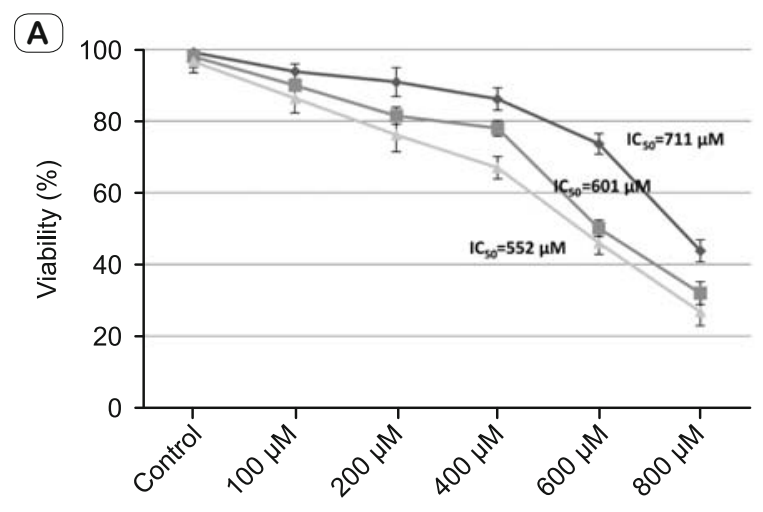

(C)

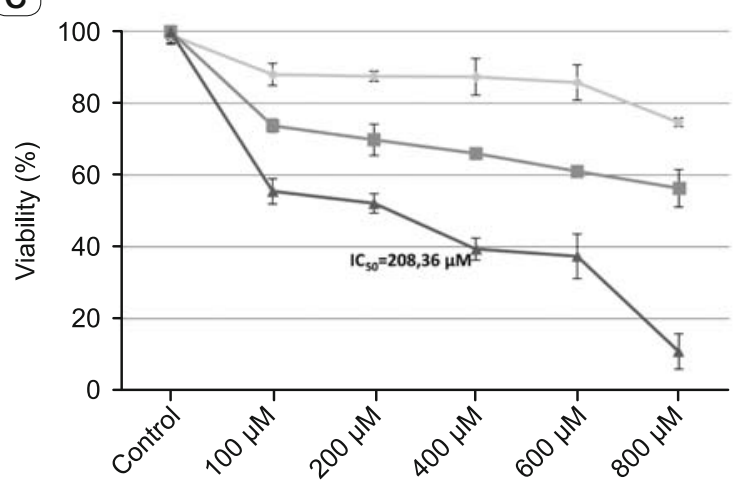

(B)

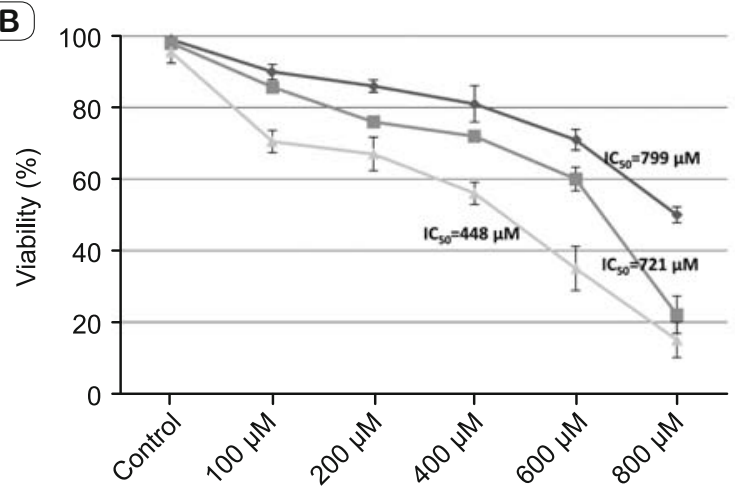

(D)

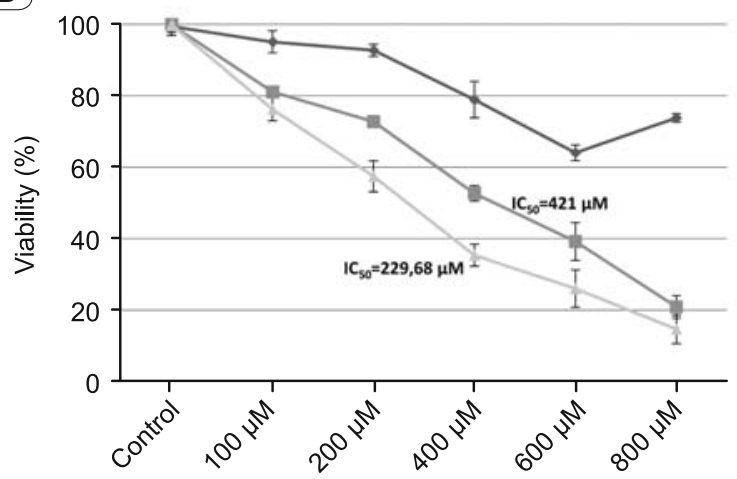

$\rightarrow 24 \mathrm{~h} \quad-48 \mathrm{~h} \quad-72 \mathrm{~h}$

Fig. 1. MTT was employed to determine the effect of thymol on the viability of PC-3, DU145, MDA-MB-231, and KLN205 cancer cells. Thymol suppressed the cell proliferation of three cancer cell lines. A. PC-3, B. DU145, C. MDA-MB-231, and D. KLN205 cells. The percentage of viable cells was calculated in comparison to untreated cells taken as $100 \%$. Data were expressed as mean $\pm \operatorname{SD}(\mathbf{p}<0.05)$.

breast adenocarcinoma cell line (MDA-MB-231) were purchased from American Type Culture Collection (ATCC) (Manasas, VA, USA). The cells were cultured in RPMI 1640 (Lonza, Basel, Switzerland) culture medium containing $10 \%$ heat-inactivated fetal bovine serum (Gibco, Invitrogen Life Technologies, Paisley, UK), $1 \%$ penicillin and streptomycin (Sigma-Aldrich, St Louis, MO, USA). The cells were cultured in $25 \mathrm{~cm}^{2}$ polystyrene flasks (Corning Life Sciences, UK) and maintained in an incubator at 37 ${ }^{\circ} \mathrm{C}$ in a humidified atmosphere in the presence of $5 \% \mathrm{CO}_{2}$. Their growth and morphology were checked microscopically daily to ensure cell health. The cells were split-passaged when they had reached confluency of approximately $80 \%$. Cells in semiconfluent flasks were harvested using $0.05 \%$ trypsin (Sigma-Aldrich) and centrifuged (Nuve NF200; Laboratory and Sterilization Technology, Ankara, Turkey) after the addition of RPMI 1640 for trypsin inactivation. After centrifugation they were resuspended in culture medium. Thymol (Sigma-Aldrich) was prepared as a 4 $\mathrm{mM}$ stock solution in dimethyl sulfoxide (DMSO). The DMSO concentration in the assay did not exceed $0.1 \%$ and was not cytotoxic to the tumor cells.

Cell viability assay

The viability of the cells was evaluated with the MTT 3-(4,5-Dimethylthiazol-2-yl)-2,5-Diphenyltetrazolium Bromide) assay. Briefly, the cells were seeded in triplicate in 96-well plates at a density of $2 \times 10^{4}$ cells/well. After $24 \mathrm{~h}$ of incubation, the cells were exposed to increasing concentrations of thymol $(0,100,200$, $400,600,800 \mu \mathrm{M})$. Then, the plates were incubated at $37^{\circ} \mathrm{C}$ in a $5 \% \mathrm{CO}_{2}$ incubator for $24 \mathrm{~h}, 48 \mathrm{~h}$ and $72 \mathrm{~h}$. Stock MTT solution (3-(4,5-dimethylthiazol-2-yl)-2,5-diphenyl tetrazolium bromide was dissolved in PBS; $5 \mathrm{mg} / \mathrm{ml})$ was added to all wells $(10 \mu 1$ for $100 \mu 1$ medium) of the assay, and the plates were incubated at 37 ${ }^{\circ} \mathrm{C}$ for $4 \mathrm{~h}$. DMSO was added to all wells and mixed thoroughly to dissolve the dark blue crystals. After a few minutes at room temperature to ensure that all crystals had been dissolved, the plates were read on a microplate reader (Bio-Rad), using a test wavelength of $570 \mathrm{~nm}$, a reference wave length of $630 \mathrm{~nm}$. 


\section{$122-128$}
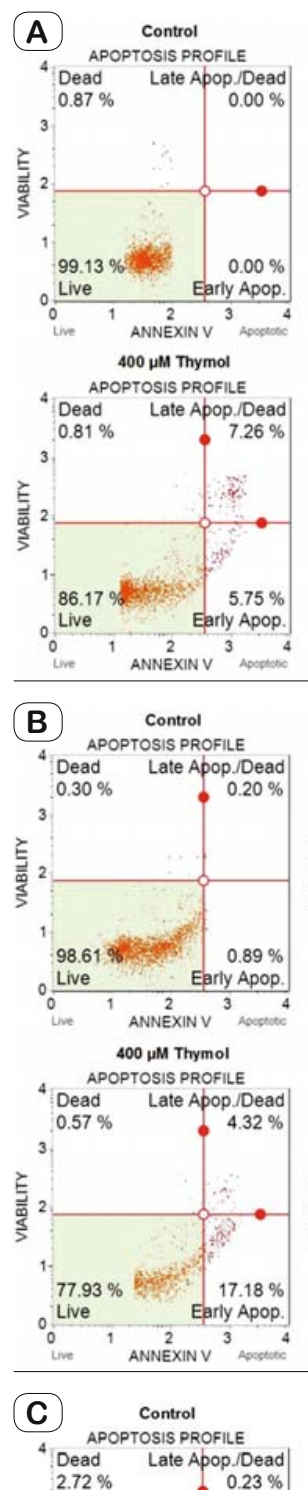

है
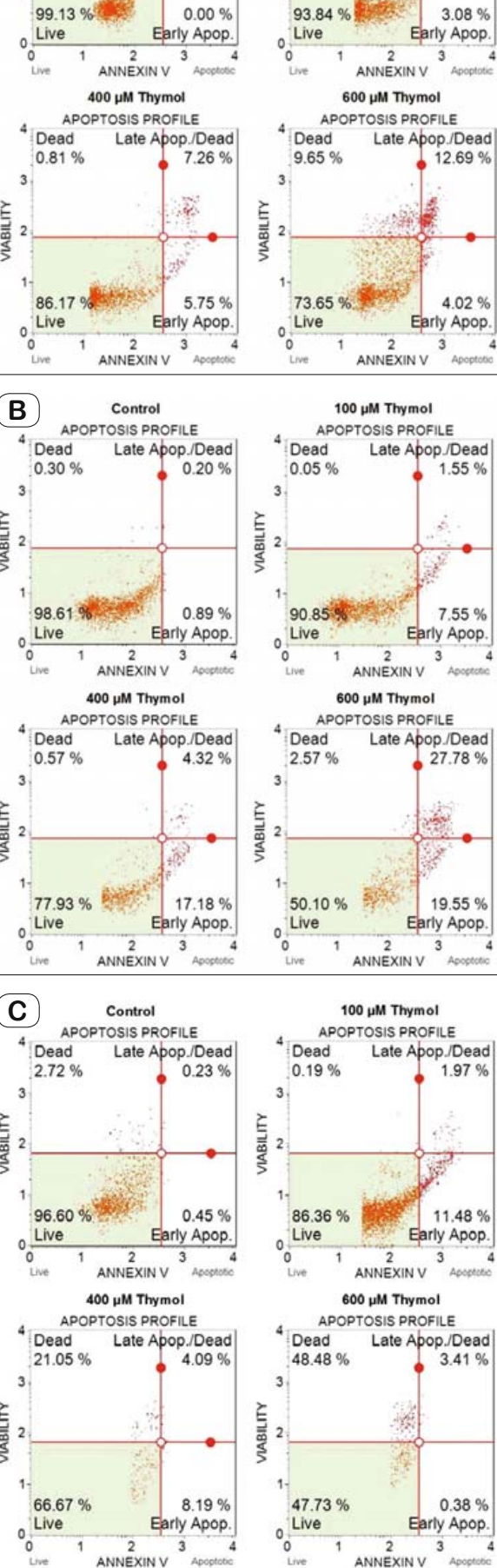
600 uM Thymol APOPTOSIS PROFILE
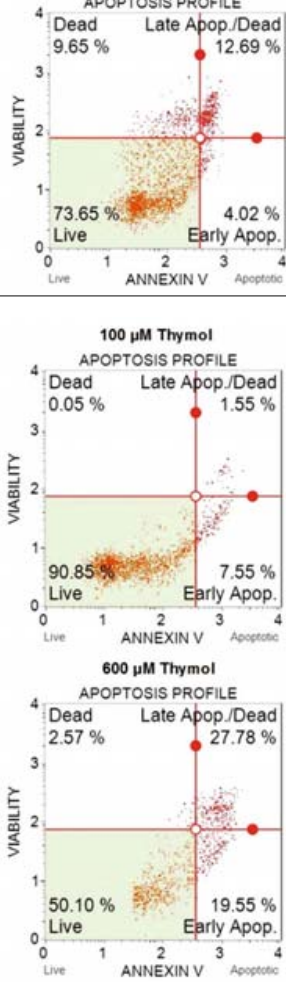

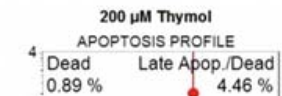

3

挋
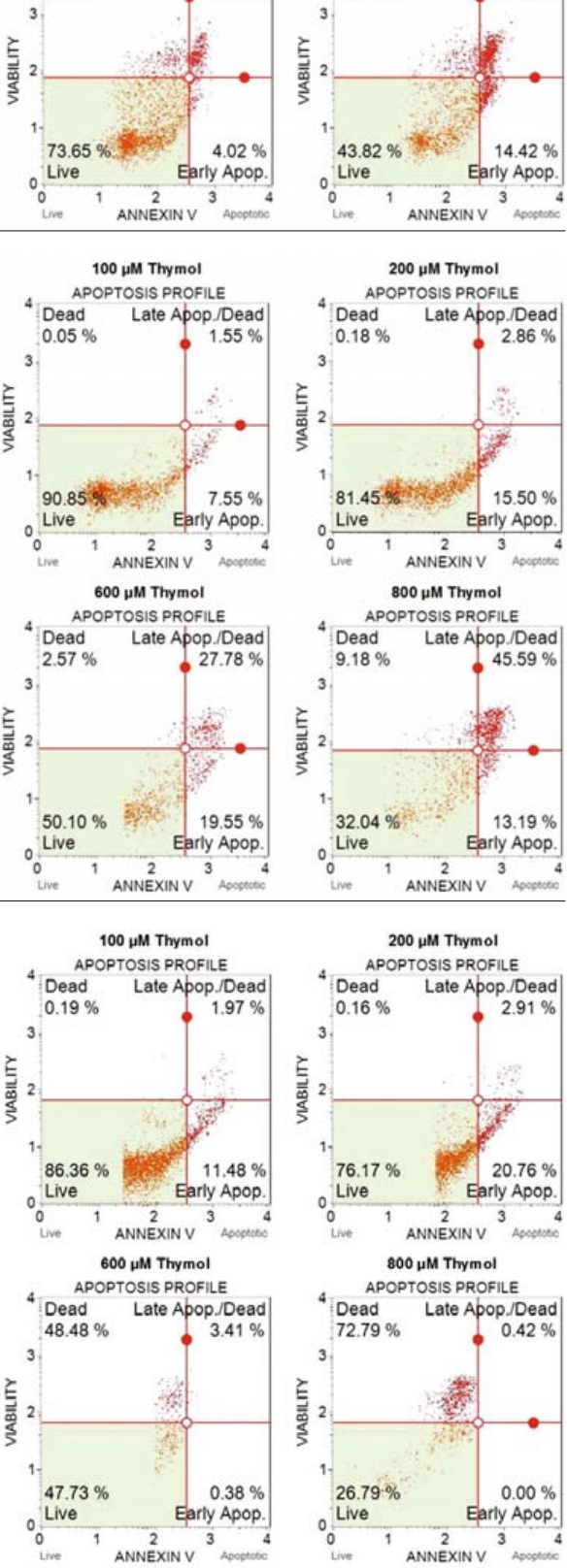

Fig. 2. Cell death analysis with Annexin V/PI staining of PC-3 human prostate cancer cell line. The non-stained population (bottom left) represents viable cells. Thymol induced apoptosis in prostate cancer cells. (A) Cells were incubated for $24 \mathrm{~h}$, (B) $48 \mathrm{~h}$, and (C) $72 \mathrm{~h}$. Data were expressed as mean \pm SD $(p<0.05)$.
Cell death analysis with Annexin V/ propidium iodide (PI) staining

The apoptotic cell profile was determined using the Muse $^{\mathrm{TM}}$ Annexin V \& Dead Cell kit (Merck) according to the manufacturer's instructions. Briefly, after treatment with thymol, all cells were collected and diluted with PBS as a dilution buffer to a concentration of $7 \times 10^{5}$ cells $/ \mathrm{ml}$. A volume of $100 \mu \mathrm{L}$ of cell suspension and $100 \mu \mathrm{L}$ of Annexin V/ dead reagent were mixed and incubated for $20 \mathrm{~min}$ at room temperature. The cells were then analyzed with Muse ${ }^{\mathrm{TM}} \mathrm{Cell}$ Analyzer (Merck Millipore). The apoptotic profile was determined by identifying four populations: (i) non-apoptotic cells, those not undergoing detectable apoptosis: Annexin V $(-)$ and 7-AAD (-), (ii) early apoptotic cells, Annexin V (+) and 7-AAD (-), (iii) late apoptotic cells, Annexin V (+) and 7-AAD (+), (iv) cells that have died through a non-apoptotic pathway: Annexin V (-) and 7-AAD (+).

\section{Statistical analysis}

All experiments were carried out in triplicate, and presented as mean $\pm \mathrm{SD}$. Statistical analysis was performed by using one-way analysis of variance, followed by Tukey's or Dunett's post hoc test. $\mathrm{p}<0.05$ was considered to indicate a statistically significant difference.

\section{Results}

\section{Effect of thymol on cell viability}

Firstly, we analyzed the effects of thymol on PC-3 and DU145 human prostate cancer cell lines. PC-3 cells were much more sensitive to the toxic effect of thymol, with $\mathrm{IC}_{50}$ (half maximal inhibitory concentration) values of $711 \mu \mathrm{M}$, $601 \mu \mathrm{M}$ and $552 \mu \mathrm{M}$, respectively. The results gained after $24 \mathrm{~h}, 48 \mathrm{~h}$ and $72 \mathrm{~h}$ of the treatment of PC-3 cancer cells are given in Figure 1a. As shown in Figure 1b, time- and dose-dependent decrease in the growth of DU145 cancer cells was observed with increasing concentrations of thymol. The $\mathrm{IC}_{50}$ values of thymol for DU145 cells were determined as $799 \mu \mathrm{M}$ after $24 \mathrm{~h}, 721 \mu \mathrm{M}$ after $48 \mathrm{~h}$ and $448 \mu \mathrm{M}$ after $72 \mathrm{~h}$. Secondly, we evaluated the effects of thymol on MDA-MB-231 human highly metastatic breast cancer line. The cells' viability decreased in a concentration-dependent manner in this cancer cell line. For all the studied doses, thymol did not show any significant cytotoxicity after $12 \mathrm{~h}$ and $48 \mathrm{~h}$. The $\mathrm{IC}_{50}$ values of cells treated with thymol were determined as $208.36 \mu \mathrm{M}$ at $72 \mathrm{~h}$ (Fig. 1c). Afterwards, we analyzed the effects of thymol on KLN205 non-small cell lung cancer cell line. KLN205 cancer cells were sensitive to thymol, and $\mathrm{IC}_{50}$ values for KLN205 cells after $48 \mathrm{~h}$ and $72 \mathrm{~h}$ were $421 \mu \mathrm{M}$ and 229,68 $\mu \mathrm{M}$, respectively (Fig. 1d).

\section{Effect of thymol on apoptosis}

Thymol significantly induced apoptosis in all cancer cell lines in a concentration-dependent manner. Statistical analyses showed a significant difference between thymol-treated 

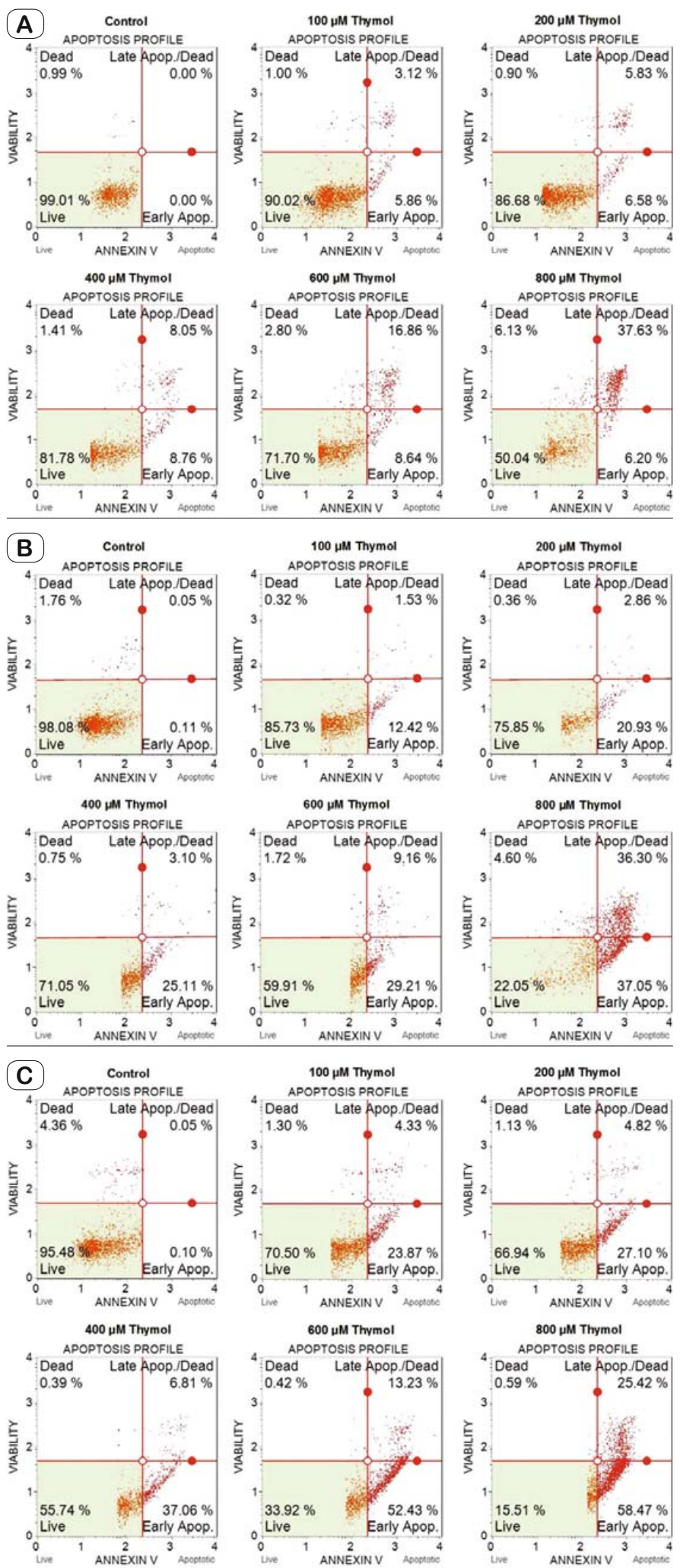

Fig. 3. Cell death analysis with Annexin V/PI staining of DU145 human prostate cancer cell line. The non-stained population (bottom left) represents viable cells. Thymol induced apoptosis in prostate cancer cells. (A) Cells were incubated for $24 \mathrm{~h},(B) 48 \mathrm{~h}$, and (C) $72 \mathrm{~h}$. Data were expressed as mean \pm SD $(p<0.05)$. cell lines compared to the control $(\mathrm{p}<0.001)$. The results show that early apoptotic cells are increased at low thymol doses in both prostate cancer cell lines (PC-3, DU145). As the concentration increased, significant increases in early apoptotic cells were observed in the DU145 cell line ( $\mathrm{p}<$ $0.001)$, while the increase in PC-3 cell line at $200 \mu \mathrm{M}$ thymol concentration was not significant after $72 \mathrm{~h}(\mathrm{p}>0.05)$. It was found that in both cell lines, the late apoptosis significantly increased in a concentration-dependent manner $(\mathrm{p}<$ 0.001 ) (Figs 2 and 3). There is no significant difference between elevated thymol concentration in MDA-MB-231 cell line and early apoptotic cells $(\mathrm{p}>0.05)$. Late apoptosis was found to be significantly increased depending on concentration ( $\mathrm{p}<0.001$ ) (Fig. 4). Our results in the KLN205 cell line show that at low thymol doses, the early apoptotic cells are increased. As the concentration increased, early apoptotic cells $(\mathrm{p}<0.001)$ and late apoptosis $(\mathrm{p}<0.001)$ were found to increase at high rates due to concentration. After 72 hours, starting from $400 \mu \mathrm{M}$ concentration, the death occurred at high rates in the cells, thus resulting in a decrease in late apoptosis (Fig. 5).

\section{Discussion}

At the present time, chemotherapy is one of the main methods of modern cancer treatment. However, most chemotherapeutic agents have various important short- and long-term side effects (14). Recently, major research has been focused on the biologically active derivatives of medicinal plants which have been considered for the development of novel potential non-toxic drugs and prevention and treatment of certain types of cancer $(10,14)$. The medicinal plants of the Lamiaceae family have been used by humans for thousands of years and have been recognized for their therapeutical properties $(15,16)$. A particular attention has been paid to the in vitro antimutagenic and anticancer properties of thyme essential oil (15).

In recent years, antiproliferative properties of thymol have been investigated. Nevertheless, its effect on cancer has not yet been fully elucidated. Several studies have been performed with extracts of Thymus spp., and a number of studies have evaluated the therapeutic effects of thymol (16). Ferraz et al (2013) evaluated the cytotoxic activity of essential oil of L. gracilis, which was chemically characterized by the presence of thymol, as major constituent on K562 (human chronic myelogenous leukemia), HepG2 (human hepatocellular carcinoma), B16-F10 (mouse melanoma), and normal peripheral blood mononuclear cell (PBMC) cell lines. Three tumor cell lines were treated for $72 \mathrm{~h}$ with increasing concentrations of essential oil and thymol. Thymol showed cytotoxicity only for B16-F10 melanoma cell line at $\mathrm{IC}_{50}$ value of $18.23 \mu \mathrm{g} / \mathrm{ml}$. The essential oil had a cytotoxic effecton both cancer cells and normal PBMC cells. Nevertheless, thymol did not show cytotoxicity to normal cells at tested concentrations (17). Similarly, Deb et al (2011) investigated 
122-128
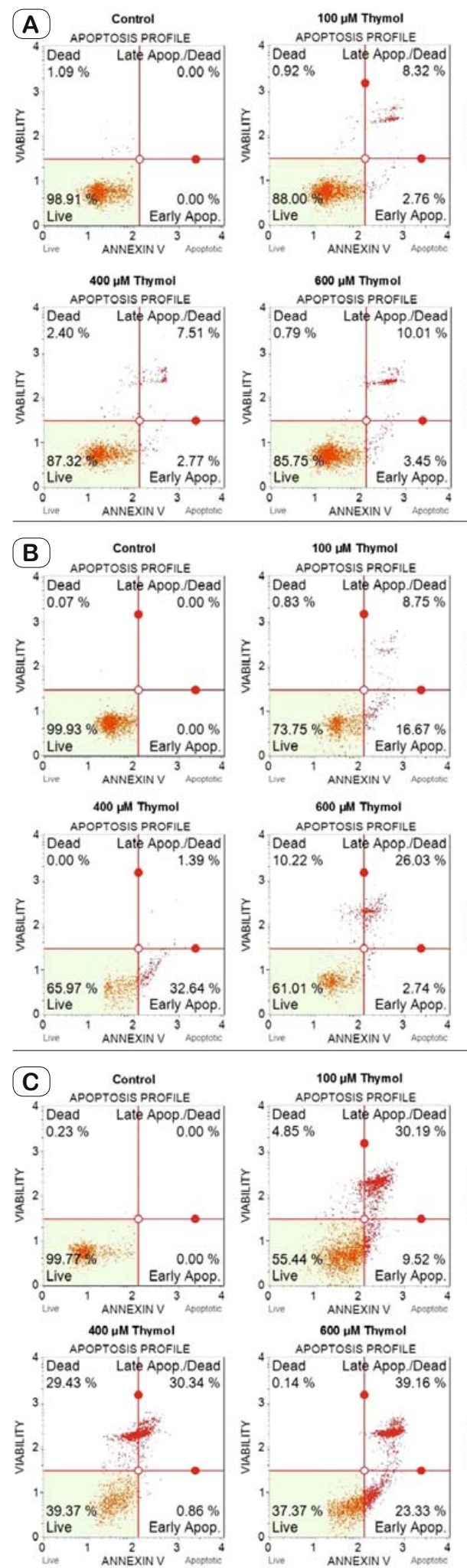
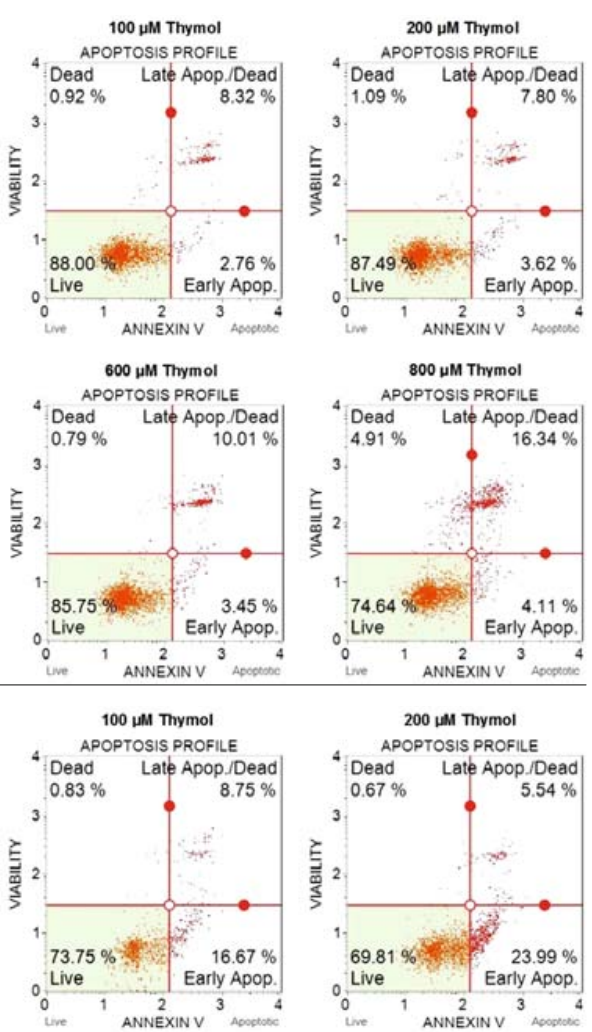

$600 \mu \mathrm{M}$ Thymol
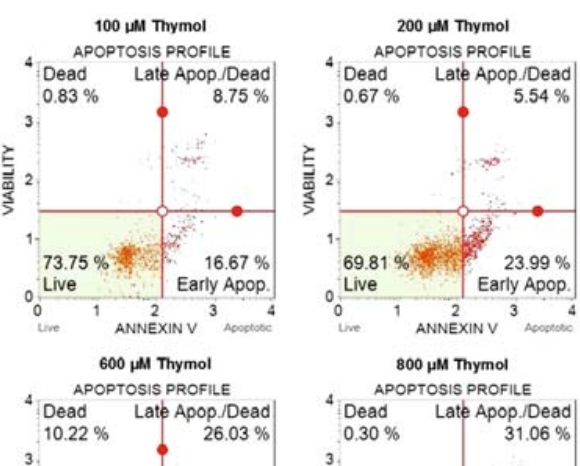

$$
3 .
$$

吾 2

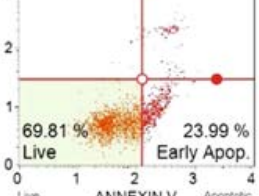

$800 \mu \mathrm{M}$ Thymol

APOPTOSIS PROFILE

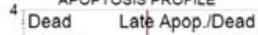

$0.30 \% \quad 31.06 \%$
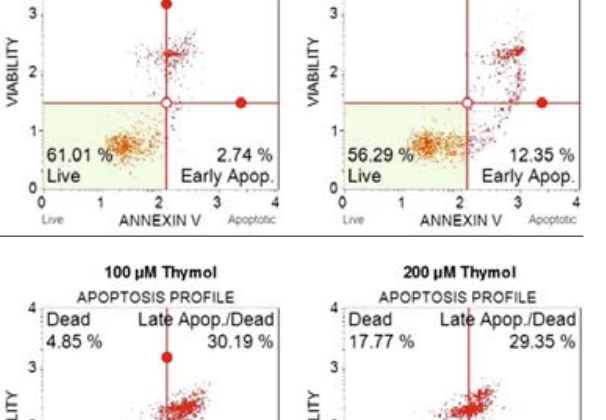

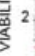

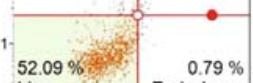

Live $0.79 \%$

$0_{0} \underbrace{2}_{\text {ANNEXINV }^{2}}{ }^{3}{ }^{2}$ 800 uM Thymol APOPTOSIS PROFILE

${ }^{4}$ Dead Late Apop./Dead

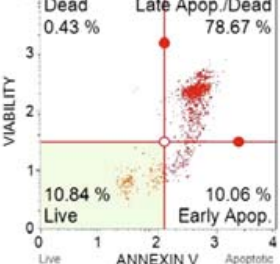

Fig. 4. Cell death analysis with Annexin V/PI staining of MDA-MB-231 human breast cancer cell line. The non-stained population (bottom left) represents viable cells. Thymol induced apoptosis in breast cancer cells. (A) Cells were incubated for $24 \mathrm{~h}$, (B) $48 \mathrm{~h}$, and (C) $72 \mathrm{~h}$. Data were expressed as mean \pm SD $(p<0.05)$.

anticancer activity of thymol on PBMC and HL-60 (human acute promyelocytic, leukemia) cells. In their study, thymol demonstrated dose-dependent cytotoxic effects on HL-60 cells after $24 \mathrm{~h}$ of exposure. However, thymol did not show any cytotoxic effect in human normal PBMC cell line like in the previous study (18). Mastelić et al (2008) reported that thymol had dose-dependent $(0.1-10 \mathrm{mM})$ antiproliferative effects on HeLa (human epithelial cervical cancer) cell line (19). Stammati et al (1999) reported that thymol has been shown to induce non-apoptotic cell death in human laryngeal carcinoma Hep- 2 cells at $\mathrm{IC}_{50}$ value of $700 \mu \mathrm{M}$ (20). Previous studies reported that thymol has cytotoxic and apoptotic effects on human gastric carcinoma cells (11), P815 mastocytoma cells (21), Caco-2 human colon adenocarcinoma cells, and HepG2 human hepatoma cells (22). The different results seen in these studies may be due to different metabolic activities of cells and methods used to measure the cytotoxic activity.

Our study has shown that thymol was cytotoxic to lung, breast, and prostate cancer cells in a concentration- and time-dependent manner. In the present study, the cytotoxic effects were remarked for PC-3 and DU145 human metastatic prostate cell line. However, we did not calculate $\mathrm{IC}_{50}$ values for MDA-MB-231 breast cancer cell line after $24 \mathrm{~h}$ and $48 \mathrm{~h}$ of exposure. The $\mathrm{IC}_{50}$ values of MDA-MB-231 breast cancer cells treated with thymol were determined as $208.36 \mu \mathrm{M}$ after $72 \mathrm{~h}$ of exposure. Similarly, we did not calculate the $\mathrm{IC}_{50}$ value for KLN205 lung cancer cell line after $24 \mathrm{~h}$ of exposure. Yet, thymol was much more effective on KLN205 cancer cells after $48 \mathrm{~h}$ and $72 \mathrm{~h}$. Our observations suggested that thymol is highly efficacious in reducing cancer cells while its growth inhibitory effect is tumor-selective.

Yeh et al (2017) reported that thymol $(100-900 \mu \mathrm{M})$ was cytotoxic to PC-3 cells in a concentration-dependent manner. Thymol also induced cell death in PC-3 cells (23). In a comprehensive study, Abed et al (2011) have analyzed the effect of thymol on two cancer (HeLa, Hep) cell lines at five concentrations $(15,30.5,61,122,244 \mathrm{ng} / \mathrm{ml})$. They observed a dose-dependent decrease in survival of two tumor cell lines. Thymol exhibited stronger cytotoxicity at a concentration of $30.5 \mathrm{ng} / \mathrm{ml}$ towards HeLa (human epithelial cervical cancer) and Hep (Human larynx epidermoid carcinoma) cell lines (24). Esmaeili-Mahani et al (2014) reported that an extract of Thymus caramanicus with major constituents of essential oil, namely with carvacrol and thymol, has a potential apoptotic and antiproliferative property against MCF-7 human breast cancer cells while a combination with vincristine, a chemotherapeutic agent, may effectively induce cell death and be a potent modality to treat this type of cancer (14). Karkabounas et al (2006) reported that the anticancer effects of carvacrol in MDA-MB-231 human metastatic breast cancer cells were based on the activation of the classical apoptosis response, including the decrease in mitochondrial membrane potential and increase in cytochrome-c release from mitochondria, increase in caspase activity, decrease in Bcl-2/Bax ratio, and 

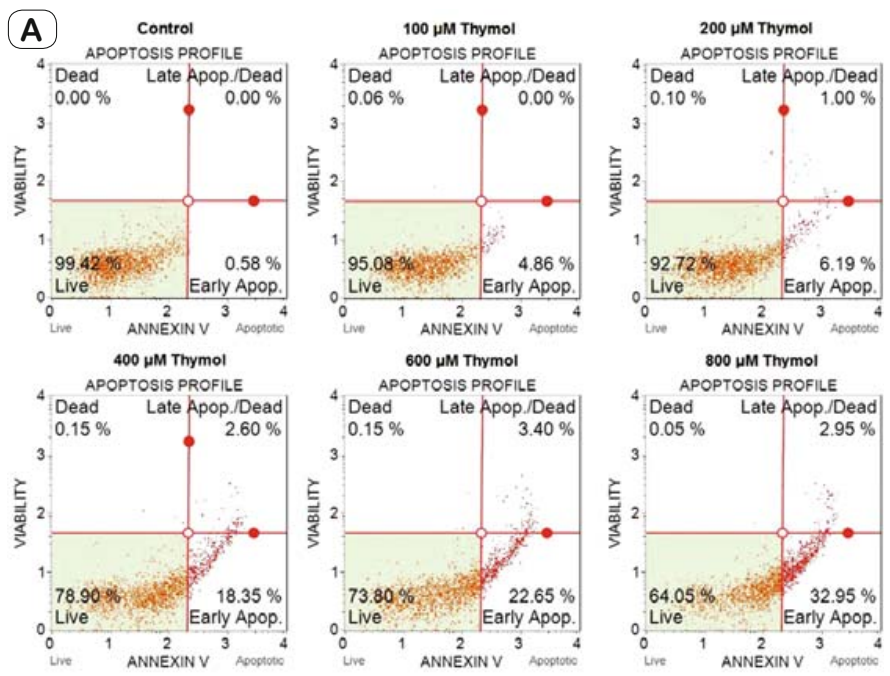

cleavage of PARP and fragmentation of DNA, which belong to the mitochondrial pathway of the apoptosis (25). Koparal et al (2003) reported that carvacrol, a monoterpene phenol, shows an anticancerogenic effect on A549 non-small cell lung cancer cell line at concentrations of 250, 500 and 1000 $1 \mathrm{M}$ after $24 \mathrm{~h}$ of exposure (26).

Apoptosis is a physiological process leading to cell death (26). The loss of control over apoptosis by excessive cell proliferation leads to the onset and progression of cancer (18). In recent years, the induction of apoptosis has become a target strategy for antitumor drug discovery (26). Deb et al (2011) reported that thymol-induced apoptosis in HL-60 cells involves both caspase-dependent and caspase-independent pathways (18). Koparal et al (2003) reported that A549 lung cancer cells treated with $100 \mathrm{lM}$ carvacrol did not show any apoptotic morphological changes after $24 \mathrm{~h}$. The cells treated with 500 and $1000 \mathrm{lM}$ carvacrol
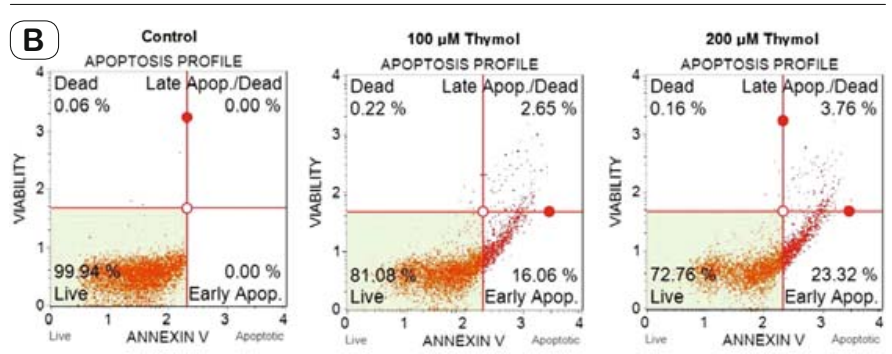
showed some apoptotic characteristics as well as morphological changes (26). Our results showed that thymol activated the apoptosis in a dose-dependent manner. Despite the fact that the usefulness of thymol in malignancy treatment is beginning to be appreciated, the mechanism of induction of apoptosis by thymol is not known. It is possible that thymol can affect both the outer coating of the cell and the cytoplasm. Their hydrophobic character appears to be responsible for disturbing the cancer cell structures which leads to the increase in cytoplasmic membrane permeability. From such data, it has been hypothesized that the cytotoxic effect of thymol on cancer cells appears to be related with apoptotic cell death.

\section{Conclusion}

In conclusion, traditional ways of treatment of lung, prostate and breast cancers have been proven effective but there are many highly undesirable side effects. Thus, there is a need for alternative chemotherapeutic agents with efficacy similar to that of conventional chemotherapy and minimal side effects. According to our data, thymol shows concentration- and time-dependent antiproliferative and apoptotic effects on non-small cell lung cancer, prostate cancer and highly metastatic human breast cancer cell lines. Not only does thymol inhibit proliferation, it also induces apoptosis in cancer cells.

\section{Learning points}

- Thymol shows antiproliferative effects via MTT analysis in prostate cancer cell lines (PC-3 and DU145), non-small cell lung cancer line (KLN205), and a highly metastatic human breast adenocarcinoma cell line (MDA-MB-231).

- Thymol has apoptotic effects on all cancer types in this study. 
$122-128$

\section{References}

1. Quisbert-Valenzuela EO, Calaf GM. Apoptotic effect of noscapine in breast cancer cell lines. Internat J Oncol 2016; 48: 2666-2674.

2. Miyake N, Chikumi H, Takata $M$ et al. Rapamycin induces p53independent apoptosis through the mitochondrial pathway in non-small cell lung cancer cells. Oncol Rep 2012; 28: 848-854.

3. Boffa DJ, Luan F, Thomas D et al. Rapamycin inhibits the growth and metastatic progression of non-small cell lung cancer. Clin Cancer Res 2004; 10: 293-300.

4. Jackson CL, Dreaden TM, Theobald LK et al. Pectin induces apoptosis in human prostate cancer cells: correlation of apoptotic function with pectin structure. Glycobiology 2007; 17 (8): 805-819.

5. Khan N, Adhami VM, Mukhtar H. Apoptosis by dietary agents for prevention and treatment of prostate cancer. Endocr Relat Cancer 2010; 17 (1): 39-52.

6. da Silva HB, Amaral EP, Nolasco EL et al. Dissecting major signaling pathways throughout the development of prostate cancer. Prostate Cancer 2013: 920612.

7. Syed DN, Khan N, Afaq F et al. Chemoprevention of prostate cancer through dietary agents: progress and promise. Cancer Epidemiol Biomarker Prevent 2007; 16: 2193-2203.

8. Gautam N, Mantha AK, Mittal S. Essential oils and their constituents as anticancer agents: a mechanistic view. BioMed Res Internat 2014: 154106.

9. Sobral MV, Xavier AL, Lima TC et al. Antitumor activity of monoterpenes found in essential oils. Sci World J 2014: 953451.

10. Arunasree KM. Antiproliferative effects of carvacrol on a human metastatic breast cancer cell line, MDA-MB231. Phytomedicine 2010; 17: 581-588.

11. Kang S-H, Kim Y-S, Kim E-K et al. Anticancer effect of thymol on AGS human gastric carcinoma cells. J. Microbiol. Biotechnol 2016; 26 (1): $28-37$.

12. Arab H-A, Fathi M, Mortezai $\mathbf{E}$ et al. Chemoprotective effect of thymol against genotoxicity induced by bleomycin in human lymphocytes. Pharm Biomed Res 2015; 1 (1): 26-31.

13. Lee KP, Kim JE, Park W-H et al. Regulation of C6 glioma cell migration by thymol. Oncol Lett 2016; 11: 2619-2624.
14. Esmaeili-Mahani S, Falahi F, Yaghoobi MM. Proapoptotic and antiproliferative effects of Thymus caramanicus on human breast cancer cell line (MCF-7) and its interaction with anticancer drug vincristine. EvidenceBased Complement Alternat Med 2014; 7.

15. Alexa E, Sumalan RM, Danciu C et al. Synergistic antifungal, allelopatic and anti-proliferative potential of Salvia officinalis L., and Thymus vulgaris L. essential oils. Molecules 2018; 23: 185.

16. Palabiyik SS, Karakus E, Halici $\mathbf{Z}$ et al. The protective effects of carvacrol and thymol against paracetamol-induced toxicity on human hepatocellular carcinoma cell lines (HepG2). Hum Exp Toxicol 2016; 35 (12): 1252-1263.

17. Ferraz RP, Bomfim DS, Carvalho NC et al. Cytotoxic effect of leaf essential oil of Lippia gracilis Schauer (Verbenaceae). Phytomed 2013; 20: 615-621.

18. Deb DD, Parimala G, Devi SS et al. Effect of thymol on peripheral blood mononuclear cell PBMC and acute promyelotic cancer cell line HL60. Chemico-Biol Interact 2011; 193: 97-106.

19. Mastelić J, Jerković I, Blazević I et al. Comparative study on the antioxidant and biological activities of carvacrol, thymol, and eugenol derivatives. J Agric Food Chem 2008; 56: 3989-3996.

20. Stammati A, Bonsi P, Zucco F et al. Toxicity of selected plant volatiles in microbial and mammalian short-term assays. Food Chem. Toxicol 1999; 37: 813-823.

21. Jaafari A, Mouse HA, Rakib EM et al. Chemical composition and antitumor activity of different wild varieties of Moroccan thyme. Braz J Pharmacogn 2007; 17 (4): 477-491.

22. Slamenová D, Horváthová E, Sramková $\mathbf{M}$ et al. DNA-protective effects of two components of essential plant oils carvacrol and thymol on mammalian cells cultured in vitro. Neoplasma 2007; 54 (2): 108-112.

23. Yeh J-H, Chou C-T, Chen I-S et al. Effect of thymol on Ca2+ homeostasis and viability in PC3 human prostate cancer cells. Chin J Physiol 2017; 60 (1): 32-40.

24. Abed RM. Cytotoxic, cytogenetics and immunomodulatory effects of thymol from Thymus vulgaris on cancer and normal cell lines in vitro and in vivo. Al-Mustansiriyah J Sci 2011; 22 (4): 41-53.

25. Karkabounas S, Kostoula OK, Daskalou T et al. Anticarcinogenic and antiplatelet effects of carvacrol. Exp Oncol 2006; 28 (2): 121-125.

26. Koparal AT, Zeytinoglu M. Effects of carvacrol on a human non-small cell lung cancer (NSCLC) cell line, A549. Cytotechnology 2003; 43: 149-154.

Received August 8, 2019. Accepted November 26, 2019. 